\title{
Taxation, risk aversion, and the wage gaps in tournaments
}

\author{
By John Douglas Skåtun
}

Department of Economics, University of Aberdeen Business School, Edward Wright Building, University of Aberdeen, Old Aberdeen, AB24 3QY, Scotland; e-mail: j.skatun@abdn.ac.uk

\begin{abstract}
In this paper's tournament model the effect of income taxes on workers' effort depends on risk preferences. At risk neutrality and low levels of worker risk aversion effort falls with higher taxes, whereas with sufficiently high risk aversion effort increases with tax rises. In the former case, firms respond to higher taxes by reducing the wage spread and by increasing it in the latter case. It sheds light on why top earners' income has risen with tax reductions over the last five decades. With females being more risk averse it suggests tax reductions contribute to the CEO gender pay gap.
\end{abstract}

JEL classification: Jo1, H31. 


\section{Introduction}

This paper presents a rank order labour tournament model, in the Lazear and Rosen (1981) tradition, ${ }^{1}$ that demonstrates the effect of a wage tax on effort depends critically upon the level of risk aversion of workers. Effort will fall with taxes if the relative risk aversion (RRA) coefficient is less than unity and will rise if the RRA exceeds one. Firms in turn respond to a tax increase by reducing the wage spread of winners and losers when the $R R A<1$ and by increasing it when the RRA $>1$. This is important for two reasons; first it gives a theoretical foundation for the observed and continuing rise in executive income levels ${ }^{2}$ and second, it contributes to an understanding of the female-male pay differential.

Whereas Bebchuk et al. (2002) suggest it is managerial power and rent seeking that has driven the rise in CEO pay, Murphy and Zábojnik (2004) argue it is due to increased competition for top executives. We offer an alternative tournament theoretical approach where taxes and the degree of risk aversion may help explain why firms have increased the wages of executives. With our results depending critically on whether the RRA is above or below unity, we appeal to empirical evidence that suggests the RRA spans unity, see the survey by Meyer and Meyer (2005). With considerable variation between individuals, see e.g. Halek and Eisenhauer (2001), Cohen and Einav (2007) and Croson and Gneezy (2009), one would expect a significant number of individuals with RRA coefficients on both sides of unity. Furthermore, there are good reasons to assume that contestants in tournaments are an adverse selection that exhibit lower levels of RRA, as reflected in Brenner (2015) who, in a large sample of US executives, find the median executive has a RRA coefficient under unity and that risk aversion is lower for higher level executives. With females in addition exhibiting less tolerance to risk than males see e.g. Levin et al. (1988) and Pålsson (1996), one could also expect to see a difference in the female-male wage differential at the upper

\footnotetext{
${ }^{1}$ See Waldman (2012) for a discussion of theory and evidence as well as Dechenaux et al. (2015) for a survey on experimental evidence.

${ }^{2}$ Over the last fifty years most OECD countries experienced top tax rate falls coupled with an increase in the top income earners' share of GDP. Atkinson and Leigh (2010), find significant effects of tax changes on the very richest and estimate the changes in the tax rates over this period can account for between one third and one half of the increase in the shares of the top $1 \%$ income groups.
} 
echelons of a firm's internal labour market structure as found in Kulich et al. (2011). Indeed, several studies such as Bartlett and Miller (1985) and Wanzenried (2008) suggest female CEO's are paid less than their male counterparts, with Elkinawy and Stater (2011) interestingly finding the difference more pronounced for lower level executives. Both the empirical findings concerning the rise in CEO pay and the female-male wage gap are consistent with our theoretical predictions.

Whilst tournament theory has been used to explain wages within the upper part of a firm hierarchy, ${ }^{3}$ it has little to say about the effect of taxes on the wage distribution with the exception of Persson and Sandmo (2005). Their surprising but intuitive insight is that firms respond to the reduction in the take home wage spread, a higher marginal tax rate implies, by increasing the pre and sometimes post tax wage distribution. Thus taxes intended to redistribute may have a perverse effect on equity. Nevertheless their result does not fit recent decades' empirical experience of increasing inequity with falling top marginal tax rates. We demonstrate their result can be reversed, to fit the data better, by the inclusion of risk aversion in a tournament model.

Risk neutrality most commonly assumed in tournament theory has the advantage of computational simplicity, usually at no sacrifice or cost. ${ }^{4}$ Indeed, the effort inducing effects arising from a higher wage spread or lower levels of noise under risk neutrality see an easy transfer to tournament models with risk aversion. Yet the application of realism through the utilisation of risk aversion really does matter to the predictions of how taxes affect tournaments.

A proportional tax imposition effectively reduces the spread of net wages of winners and losers in a tournament. It therefore reduces effort levels of risk neutral competitors. With risk aversion and diminishing marginal utility this conclusion does not always follow. Whilst the imposition of taxes reduces the monetary difference between winning and losing, it also reduces the state contingent income levels to where the marginal utility is greater. Thus, though the wage

\footnotetext{
${ }^{3}$ A large number of papers such as Baker et al. (1994) find most hiring occurs at the lower levels of a firm. This suggests that the internal labour markets of tournament models are more relevant in explaining pay structures at the higher levels of a firm's hierarchy where there is less use of outside hires.

${ }^{4}$ Whilst the initial rank order tournament exposition by Lazear and Rosen (1981) discusses risk aversion, most papers in the subsequent literature assume risk neutrality with little loss of generality. There are however some notable exceptions of studies that incorporate risk aversion, such as Kräkel (2008) who investigates risk taking in tournaments, and Green and Stokey (1983) who contrast the outcomes of contracts and tournaments.
} 
spread falls, the spread in utility may sometimes rise. Hence, taxes may increase the supply side effort level of workers rather than decrease it as previously found. ${ }^{5}$ This then has important implications for how the firm sets the wage gap in tournaments, as will be demonstrated below.

\section{Tournament effort with risk aversion and taxes.}

We proceed with a straightforward pair-wise theoretical tournament model, allowing for risk averse and risk neutral worker attitudes. Two identical workers denoted $i$ and $j^{6}$ within a firm each choose effort level $\mu_{\mathrm{i}}$ and $\mu_{\mathrm{j}}$ respectively in response to the winner being rewarded the net income $y_{1}$ and the loser being paid the net income $y_{2}$. Their firm cannot witness effort directly but observes instead the worker outputs, $\mathrm{q}_{\mathrm{i}}$ and $\mathrm{q}_{\mathrm{j}}$. These outputs are however only imperfect proxies for effort: $q_{i}=\mu_{i}+\varepsilon_{i}$ and $q_{j}=\mu_{j}+\varepsilon_{j}$, where the random noise (luck) components are given by $\varepsilon_{i}$ and $\varepsilon_{j}$. Following the convention of the literature we assume the random noise components cannot be ascertained by workers in advance of effort being exerted. The winner is the worker with the highest output, which varies due to the random noise, in a symmetric Nash equilibrium with agents choosing identical effort levels; $\mu_{i}=\mu_{j}$.

We adopt the objective function common in the literature; separable in income and effort where the workers' objective function is comprised of the expected utility of the tournament 'gamble' net of the cost of effort. ${ }^{7}$ The maximisation problem of worker i involves choosing the effort level that maximises the objective function $\mathrm{V}_{\mathrm{i}}$ :

$\begin{gathered}\operatorname{Max} \\ \mu_{i}\end{gathered} \quad V_{i}=p u\left(y_{1}\right)+(1-p) u\left(y_{2}\right)-C\left(\mu_{i}\right)$

\footnotetext{
${ }^{5}$ It may also affect the incentives for sabotage in tournaments. See the seminal work by Lazaer (1989) as well as the survey by Chowdhury and Gürtler (2015). Whilst such sabotage activities may be interesting, we abstract away from such issues as they are not the focus of this paper.

${ }^{6}$ Hence the analysis is restricted to workers who are in all respects identical and does not consider the potential interesting case of heterogeneity in risk aversion. Whilst there are no tournament models dealing with heterogeneity in risk aversion some papers such as Bhattacharya and Guasch (1988) consider tournaments with differences in worker ability.

${ }^{7}$ Thus our results are for instance directly comparable to the risk neutral tax analysis of Persson and Sandmo (2005).
} 
Where $\mathrm{p}$ is the probability of winning the tournament, $\mathrm{u}($.$) is the utility; increasing and$ concave in state dependent income and $C($.$) is the cost as an increasing but convex function of$ effort. Worker i chooses the effort as characterised by the following first order condition:

$\frac{\partial V_{i}}{\partial \mu_{i}}=\frac{\partial p}{\partial \mu_{i}}\left(u\left(y_{1}\right)-u\left(y_{2}\right)\right)-C^{\prime}\left(\mu_{i}\right)=0$

Note the probability $p \equiv \operatorname{prob}\left(q_{i}>q_{j}\right)$ that worker $i$ wins the tournament equates to the cumulative distribution function, $\mathrm{G}$, of the random variable $\varepsilon_{j}-\varepsilon_{i}$, since: $\mathrm{p}=\operatorname{prob}\left(\mu_{i}+\varepsilon_{i}>\mu_{j}+\right.$ $\left.\varepsilon_{j}\right)=\operatorname{prob}\left(\mu_{i}-\mu_{j}>\varepsilon_{j}-\varepsilon_{i}\right)=\mathrm{G}\left(\varepsilon_{j}-\varepsilon_{i}\right)$. It follows that $\frac{\partial p}{\partial \mu_{i}}=\frac{\partial G(0)}{\partial \mu_{i}}=g(0)$. We can therefore rewrite (2) as: $g(0)\left(u\left(y_{1}\right)-u\left(y_{2}\right)\right)-C^{\prime}\left(\mu_{i}\right)=0$. The traditional result that effort will rise with a reduction of the importance of luck (an increase in $\mathrm{g}(0)$ ) then follows directly. In addition, the usual tournament result that effort increases when the spread of payments widens translates easily to the risk aversion case, since an increase in the pay spread increases $u\left(y_{1}\right)-u\left(y_{2}\right)$.

When taxes are introduced we note that the tournament firm merely sets wages, and not the after tax income levels $\mathrm{y}_{1}$ and $\mathrm{y}_{2}$. Let the respective winning and losing disposable incomes be defined by; $\mathrm{y}_{1}=(1-t) \mathrm{w}_{1}$ and $\mathrm{y}_{2}=(1-t) \mathrm{w}_{2}$, where $\mathrm{w}_{\mathrm{i}}$ is the pre-tax state contingent wage and $\mathrm{t}$ is the marginal tax on labour income. ${ }^{8}$ We can now evaluate the effect of wages on effort:

$\frac{d \mu_{i}}{d w_{1}}=\frac{g(0)(1-t) u^{\prime}\left(y_{1}\right)}{-\frac{\partial^{2} V_{i}}{\partial \mu^{2}}} \neq \frac{d \mu_{i}}{d w_{2}}=\frac{g(0)(1-t) u^{\prime}\left(y_{2}\right)}{\frac{\partial^{2} V_{i}}{\partial \mu^{2}}} \quad \rightarrow \frac{d \mu_{i}}{d w_{1}}=-\frac{u^{\prime}\left(y_{1}\right)}{u^{\prime}\left(y_{2}\right)} \frac{d \mu_{i}}{d w_{2}}$

Expression (3) implies the effect on effort of reducing the losers' income will be stronger than the effect on effort of an increase of the winner's income. ${ }^{9}$ As incentives are the strongest at lower wages, it could imply a tougher race to the bottom than is found in the risk neutral literature. Thus, firms now prefer a wage spread with lower average wages for effort consideration alone, whilst being restricted from setting wages too low by the workers' participation constraint.

We can now total differentiate expression (2) to derive the effect of taxes on effort:

\footnotetext{
${ }^{8}$ Thus we investigate a proportional tax rate imposition. All the results presented here can be shown to hold for the progressive taxation case as is demonstrated in Skåtun (2016), who also investigates the balanced budget case. ${ }^{9}$ Where $\frac{\partial^{2} V_{i}}{\partial \mu_{i}{ }^{2}}=\frac{\partial^{2} p}{\partial \mu_{i}{ }^{2}}\left(u\left(y_{1}\right)-u\left(y_{2}\right)\right)-C^{\prime \prime}\left(\mu_{i}\right)<0$ is a required second order condition to assure maximisation. Higher order derivatives of this objective function are assumed to be equated to zero in the remainder.
} 
$\frac{d \mu_{i}}{d t}=\frac{-g(O)\left(\left(w_{1}\right) u \prime\left(y_{1}\right)-\left(w_{2}\right) u \prime\left(y_{2}\right)\right)}{-\frac{\partial^{2} V_{i}}{\partial \mu_{i}{ }^{2}}}$

With risk neutrality, where $\mathrm{wu}^{\prime}(\mathrm{y})=\mathrm{w}$, it follows that since $\mathrm{w}_{1}>\mathrm{w}_{2}$ that the sign of expression (4) is less than zero. In this case a proportional tax rate increase would reduce the level of effort. However this does not necessarily hold under risk aversion. From (4) we have:

$\frac{d \mu_{i}}{d t} \gtreqless 0$ if $w_{1} u^{\prime}\left(y_{1}\right)-w_{2} u^{\prime}\left(y_{2}\right) \lesseqgtr 0$

With $w_{1}>w_{2}$ this in turn implies:

$\frac{d \mu_{i}}{d t} \gtreqless 0$ if $\frac{\partial\left(w u^{\prime}(y)\right)}{\partial w} \lesseqgtr 0$

With the relative risk aversion coefficient given by $\mathrm{RRA}=-\frac{y u^{\prime \prime}(y)}{u^{\prime}(y)}$, the condition as given by expression (5b) therefore depends on:

$\frac{\partial\left(w u^{\prime}(y)\right)}{\partial w}=u^{\prime}(y)+(1-t) w u^{\prime \prime}(y)$

$=u^{\prime}(y)+((1-t) w) u^{\prime \prime}(\mathrm{y})$

$=u^{\prime}(y)(1-R R A)$

From expression (6) it follows that $\frac{d \mu_{i}}{d t} \gtreqless 0$ if RRA $\gtreqless$. Thus effort will increase in response to rising proportional tax rates as long as the relative risk aversion coefficient exceeds unity. Despite the fact that the wage spread is decreasing, the more risk averse participant, with a RRA exceeding unity, will seek more self-protection by opting for higher effort levels. The converse is true for lower relative risk aversion coefficients, below unity. The overall effect of a tax increase on the spread of utility is a compound effect: Though a tax increase always renders the worker worse off irrespective of the risk aversion coefficient, it also will increase the spread between winning and losing in terms of utility for sufficiently concave, that is RRA $>1$, utility functions. This will therefore have the novel effect of increasing effort in response to higher taxes. It is this simple intuitive result that sets this paper apart from previous literature and drives some of the remaining results. ${ }^{10}$

\footnotetext{
${ }^{10}$ Our unusual result that effort could increase in response to a reduced spread of after tax wages, is similar in intuition to Dionne and Eeckhoudt (1985) and Konrad and Skaperdas (1993), who find that the level of selfprotection may fall with higher risk-aversion. By extension it is also related to Skaperdas and Gan (1993), who find that more risk averse participants in contests of limited liability exert higher effort than the less risk averse
} 
In addition taxes will also influence the effectiveness of wage spreads on effort:

$\frac{\partial^{2} \mu_{i}}{\partial w_{1} \partial t}=\frac{-g(0)\left((1-t) w_{1} u^{\prime \prime}\left(y_{1}\right)+u^{\prime}\left(y_{1}\right)\right)}{-\frac{\partial^{2} V_{i}}{\partial \mu_{i}{ }^{2}}}=\frac{-g(0) u^{\prime}\left(y_{1}\right)(1-R R A)}{-\frac{\partial^{2} V_{i}}{\partial \mu_{i}{ }^{2}}} \gtreqless 0$ when $R R A \gtreqless 1$
$\frac{\partial^{2} \mu_{i}}{\partial w_{2} \partial t}=\frac{g(0)\left((1-t) w_{2} u^{\prime \prime}\left(y_{2}\right)+u^{\prime}\left(y_{2}\right)\right)}{-\frac{\partial^{2} V_{i}}{\partial \mu_{i}{ }^{2}}}=\frac{g(0) u^{\prime}\left(y_{2}\right)(1-R R A)}{-\frac{\partial^{2} V_{i}}{\partial \mu_{i}{ }^{2}}} \lesseqgtr 0$ when $R R A \gtreqless 1$

When the RRA is greater (less) than one, we know from expression (6) that effort will rise (fall) with taxes. From expressions (7a) and (7b) we now deduce an increase in tax magnifies the effect a change in the wage spread has on effort when the RRA is greater than unity. Here an increase in the wage spread will have a bigger effect on effort when taxes are high. In contrast, when the RRA is less than one, the wage spread effect on effort is dampened by higher taxes. The effects of expressions (7a) and (7b) together with the effects given by expression (6) signify the key transmission effects taxes have on a firm's choice of wage spread, which we now discuss next.

\section{The choice of wage spread.}

So far this study has been restricted to the supply side only. By now incorporating the firm's demand side decisions we are able to close the model and pin down the wage distribution at the top end of the firm's hierarchy. When the profit maximising firm sets the wage spread in the tournament it does so in the full knowledge that workers will respond in accordance to Section 2. Noting the expected output is identical to effort and normalising prices to one, the ex ante profit the firm derives from each worker is simply the effort less the expected average wage. To optimize, the firm seeks to maximize its profit, $\pi$, subject to the workers' participation constraint. Thus the firm must satisfy the constraint which specifies the worker value, $V$, of a tournament has to exceed his outside (employment) option $\bar{V}$.

$$
\begin{aligned}
& \operatorname{Max}_{W_{1}, W_{2}} \quad \pi=\mu-\left(\frac{1}{2} w_{1}+\frac{1}{2} \mathrm{w}_{2}\right) \\
& \text { s.t. } \quad p u\left((1-t) w_{1}\right)+(1-p) u\left((1-t) w_{2}\right)-C(\mu) \geq \bar{V}
\end{aligned}
$$

contestants. Furthermore it relates to Kvaløy and Olsen (2015), who show that uncertainty in the enforcement of contracts may lead to less effort but stronger incentives being offered by firms. This they argue has the potential of generating a negative association of effort and performance related pay.

${ }^{11}$ We henceforth drop the subscript $i$, as all workers are identical. 
A standard Lagrangean $\mathcal{L}$, with the associated Lagrangean multiplier $\lambda$, is then defined. Optimisation follows simply and is reflected in the resulting first order conditions:

$$
\begin{aligned}
& \frac{\partial \mathcal{L}}{\partial \lambda}=\bar{V}-\left\{p u\left((1-t) w_{1}\right)+(1-p) u\left((1-t) w_{2}\right)-C(\mu)\right\}=0 \\
& \begin{aligned}
\frac{\partial \mathcal{L}}{\partial w_{1}} & =\frac{\partial \pi}{\partial w_{1}}-\lambda \frac{\partial V}{\partial w_{1}} \\
& =\frac{\partial \mu}{\partial w_{1}}-\frac{1}{2}-\lambda\left(p(1-t) u^{\prime}\left(y_{1}\right)+\frac{\partial \mu}{\partial w_{1}}\left(\frac{\partial p}{\partial \mu}\left(u\left(y_{1}\right)-u\left(y_{2}\right)\right)-C^{\prime}\left(\mu_{i}\right)\right)\right)=0 \\
\frac{\partial \mathcal{L}}{\partial w_{2}} & =\frac{\partial \pi}{\partial w_{2}}-\lambda \frac{\partial V}{\partial w_{2}} \\
& =\frac{\partial \mu}{\partial w_{2}}-\frac{1}{2}-\lambda\left((1-p)(1-t) u^{\prime}\left(y_{2}\right)+\frac{\partial \mu}{\partial w_{2}}\left(\frac{\partial p}{\partial \mu}\left(u\left(y_{1}\right)-u\left(y_{2}\right)\right)-C^{\prime}(\mu)\right)\right)=0
\end{aligned}
\end{aligned}
$$

This system of equations then characterises the chosen wage spread. To proceed we make three observations. First, the identical workers have an equal probability of winning, that is $\mathrm{p}=1 / 2$. Second, by the envelope theorem we have $\frac{\partial p}{\partial \mu}\left(\left(u\left(y_{1}\right)-u\left(y_{2}\right)\right)-C^{\prime}(\mu)\right)=0$. Third, the tax incidence is symmetric so that taxes affect the tournament and outside option in equal measures, that is $\frac{d V}{d t}=\frac{d \bar{V}}{d t} \cdot 12$ There are two separating cases to consider; first when $\mathrm{RRA}<1$ and second when $\mathrm{RRA}>1$

\subsection{Case 1; when RRA<1.}

We refer to the appendix that demonstrates $\frac{d w_{1}}{d t}<0$ when $R R A<1$. In this case, of relative low risk aversion, an increase in taxes will reduce the wages that are offered to winning workers by the firm. We also note from the appendix that $\frac{d w_{2}}{d t}>0$, when $R R A<1$. That is, as taxes increase the firm will increase the losers' wage, when the workers have low levels of risk aversion.

We now denote the before tax wage spread as $R=\frac{w_{1}}{w_{2}} \cdot{ }^{13}$ The effect on this wage spread of an increase in tax-rates can be shown to be given as: $\frac{d R}{d t}=\frac{\frac{d w_{1}}{d t} w_{2}-w_{1} \frac{d w_{2}}{d t}}{w_{2}{ }^{2}}$. This is unambiguously

\footnotetext{
${ }^{12}$ This is an application of the envelope theorem. By assuming the workers optimise their effort within the firm as well as in the outside option firm we have $\frac{d V}{d \mu}=0$ and $\frac{d \bar{V}}{d \mu}=0$. Thus it then follows that $\frac{d V}{d t}=\frac{d V}{d \mu} \frac{d \mu}{d t}=0$ and $\frac{d \bar{V}}{d t}=\frac{d \bar{V}}{d \mu} \frac{d \mu}{d t}=0$.

${ }^{13}$ Using this definition implies the before and after tax wage spread is the same; $R=\frac{w_{1}}{w_{2}}=\frac{(1-t) w_{1}}{(1-t) w_{2}}$. Such equivalence does not hold for all other measures, as the simple difference in gross and net wages between winning
} 
negative as long as RRA $<1$. It is now evident the before tax wage distribution, between winners and losers, narrows with an increase in tax. Intuitively, the relative gain between winning and losing falls with higher taxes when the relative risk aversion coefficient is low enough. This then implies, that if the relative risk aversion coefficient is less than unity, effort falls, as is demonstrated by expression (6). Hence the relative gain to the firm of increasing wage dispersion falls for the firm, as reflected by expressions (7a) and $(7 \mathrm{~b})$ when $R R A<1$. Firms therefore reduce the wage spread in response to higher taxes when risk aversion is low. For the sake of completeness it is a result that also holds in the limit when the worker is risk neutral. ${ }^{14}$ Thus taxes that may have been introduced to redistribute funds to the poor, have the added equity benefit of compressing wages at the top end. It therefore similarly follows that reducing taxes will cause an unambiguous rise in inequality.

Note now that this case results, when taken together with Brenner's (2015) finding that top executives have RRA's falling short of unity, in a consistency with the empirical regularity of tax rates and top income earnings being negatively correlated. Indeed, it follows from the above theoretical results that reductions in taxes will imply top earners, the winners of the tournament, will earn more both before and after taxes. As taxes fall the top earners increase their effort, leading the firms to respond by increasing the wage spread in the tournament.

Whilst Case 1 fits the firm's upper echelons well, the effect of the tax reduction on wages lower down a firm hierarchy may be less easy to ascertain. We note that this complexity mirrors the empirical results of Saez (2004) who finds significant effects of the marginal tax rate on the top $1 \%$ of US earners' income share, whilst very small effects on the top $1 \%-5 \%$ and the top 5\%-10\% earner's income share. In his and in our paper; clarity and the effect of taxes on wages is more striking for the top earners, whilst matters are more complex lower down the income distribution.

\subsection{Case 2; when RRA $>1$.}

and losing demonstrates; $w_{1}-w_{2} \neq(1-t) w_{1}-(1-t) w_{2}$. Whilst the application of either of these two measures makes no difference to the conclusions to the before and after wage spreads of Case 1 , it matters for Case 2, where the changes in after tax wage spread is indeterminate when using the latter measure.

${ }^{14}$ Whilst this at first appears to contradict Persson and Sandmo (2005), it should be noted their result was predicated on a balanced budget approach in contrast to the unbalanced budget framework in the present model. For further discussion see Skåtun (2016). 
When on the other hand RRA $>1$ the results are diametrically opposed to Case 1 . Note it follows from expression (6), for the more risk averse with an RRA $>1$, that effort increases with higher taxation, that is $\frac{d \mu}{d t}>0$. The appendix now shows $\frac{d w_{1}}{d t}>0$, and $\frac{d w_{2}}{d t}<0$, when RRA $>1$. The effect of taxes on the wage spread, $\frac{d R}{d t}=\frac{\frac{d w_{1}}{d t} w_{2}-w_{1} \frac{d w_{2}}{d t}}{w_{2}{ }^{2}}$ is therefore unambiguously positive as long as RRA $>1$. Here the firms respond to higher tax rates by increasing the wage spread. This again reflects expressions (7a) and (7b) where the effect of increasing the wage spread is amplified by higher taxes when RRA $>1$. Any increase in taxation for redistributive purposes would in this case of relative high risk aversion lead to the unintended perverse consequence of increasing the spread between the winner and loser of wage contests, which in turn could lead to within firm inequality.

A response to a drop in taxes could perversely be met by a reduction of effort in this case, that leads the firm to find it less profitable to maintain a high wage spread. The firm therefore could choose to offer a more compressed tournament wage structure to the more risk averse following a fall in taxes. If firms are able to statistical discriminate between groups, it could turn out to have important equity implications. For the winning individuals belonging to more risk averse groups, such as females and non-executives, could very well see the gains of winning a tournament being diminished with falling taxes.

\section{Conclusion and discussion.}

This paper has provided a new theoretical reason for the rise in top executive pay and has shed light on the female-male pay differential. We have shown that tournament workers' risk attitudes are important in determining their supply side effort response to changes in labour taxes. This in turn influences the firm's choice of the wage spread within tournaments, which should narrow with taxes for the less risk averse participant and widen with the more risk averse participant. Whilst the analysis sheds light on the inequity of female-male pay levels, a certain sense of fairness in regards to effort within a gender follows. Taxes reduce effort levels for low risk aversion workers who are then doubly punished: Initially by the lower disposable income and then 
by the firm's response of further lowering the winner's wage. This is in contrast to highly risk averse individuals who respond to higher taxes by increasing their effort, for which they are partially compensated by an increase in their top earning wage. Thus though this study demonstrates how complex the tax effects under risk aversion can be, the positive relationship between tournament effort and the winning worker's wage remains.

The analysis has precluded certain aspects that could form the basis of future research. One limitation is the exclusion of the possibility of heterogeneity amongst the tournament participants. Removing this restriction, by allowing contestants in the pairwise tournament model to have different levels of risk aversion, opens an interesting but unexplored avenue of research. The analysis could also be further extended by applying the framework to work place sabotage issues. Finally, the work presented above has been purely theoretical. Empirical validation of the model could be sought either by investigating work place data or by designing experiments. Such potentially promising topics for research are left for future study.

\section{ACKNOWLEMENTS}

I would like to thank two anonymous referees for their constructive comments. Any errors remaining are my own.

\section{References}

Atkinson, A. B. and Leigh, A. (2010) The distribution of top incomes in five Anglo-Saxon countries over the twentieth century, IZA-Discussion Paper Series, No. 4937. Bonn.

Baker, G., Gibbs, M., and Holmstrom, B. (1994) The wage policy of a firm, Quarterly Journal of Economic, 109, 921-955.

Bartlett, R. L. and Miller, T. I. (1985) Executive compensation: Female executives and networking, American Economic Review, Papers and Proceedings, 75, 266-27o.

Bhattacharya, S. and Guasch, J. L. (1988) Heterogeneity, tournaments, and hierarchies, Journal of Political Economy, 96, 867-881.

Bebchuk, L. A., Fried, J., and Walker, D. (2002) Managerial power and rent extraction in the design of executive compensation, University of Chicago Law Review, 69, 751-846.

Brenner, S. (2015) The risk preferences of US executives, Management Science, 61, 1344-1361.

Chowdhury, S. M. and Gürtler, O. (2015) Sabotage in contests: A survey, Public Choice, 164, 135155 .

Cohen, A. and Einav, L. (2007) Estimating risk preferences from deductible choice, American Economic Review, 97, 745-788. 
Croson, R. and Gneezy, U. (2009) Gender differences in preferences, Journal of Economic Literature, 47, 1-27.

Dechenaux, E., Kovenock, D., and Sheremeta, R. M. (2015) A survey of experimental research on contests, all-pay auctions and tournaments, Experimental Economics, 18, 609-669.

Dionne, G. and Eeckhoudt, L. (1985) Self-insurance, self-protection and increased risk aversion, Economics Letters, 17, 39-42.

Elkinawy, S. and Stater, M. (2011) Gender differences in executive compensation: Variation with board gender composition and time, Journal of Economics and Business, 63, 23-45.

Green, J. R. and Stokey, N. L. (1983) A comparison of tournaments and contracts, Journal of Political Economy, 91, 349-364.

Halek, M. and Eisenhauer, J. G. (2001) Demography of risk aversion, Journal of Risk and Insurance, 68, 1-24.

Konrad, K. A. and Skaperdas, S. (1993) Self-insurance and self-protection: A non-expected utility analysis, The GENEVA Papers on Risk and Insurance Theory, 18, 131-146.

Kräkel, M. (2008) Optimal risk taking in an uneven tournament game with risk averse players, Journal of Mathematical Economics, 44, 1219-1231.

Kulich, C., Trojanowski, G., Ryan, M. K., Haslam, S. A., and Renneboog, L. D. R. (2011) Who gets the carrot and who gets the stick? Evidence of gender disparities in executive remuneration, Strategic Management Journal, 32, 301 - 321.

Kvaløy, O. and. Olsen, T. E. (2015) The tenuous relationship between effort and performance pay, Journal of Public Economics, 121, 32-39.

Lazear, E. P. (1989) Pay equality and industrial politics, Journal of Political Economy, 97, 561-580.

Lazear, E. P. and Rosen, S. (1981) Rank-order tournaments as optimum labor contracts, Journal of Political Economy, 89, 841-864.

Levin, I. P., Snyder, M. A., and Chapman, D. P. (1988) The interaction of experiential and situational factors and gender in a simulated risky decision-making task, Journal of Psychology, 122, 173-181.

Meyer, D. J. and Meyer, J. (2005) Relative risk aversion: What do we know?, Journal of Risk and Uncertainty, 31, 243-262.

Murphy, K. J. and Zábojnik, J. (2004) CEO pay and appointments: A market-based explanation for recent trends, American Economic Review, Papers and Proceedings, 94, 192-196.

Persson, M. and Sandmo, A. (2005) Taxation and tournaments, Journal of Public Economic Theory, 7, 543-559.

Pålsson, A. (1996) Does the degree of relative risk aversion vary with household characteristics?, Journal of Economic Psychology, 17, 771-787.

Saez, E. (2004) Reported incomes and marginal tax rates, 1960-2000: Evidence and policy implications, NBER Working Paper 10273, National Bureau of Economic Research, Cambridge, Massachusett.

Skaperdas, S. and Gan, L. (1995) Risk aversion in contests, Economic Journal, 105, 951-962.

Skåtun, J. D. (2016) Tournaments, risk aversion and taxation, Discussion Paper in Economics,, vol. 16, no. 6, University of Aberdeen Business School, Aberdeen.

Waldman, M. (2012), Theory and evidence in internal labor markets, in R. Gibbons and J. Roberts (eds) The Handbook of Organizational Economics, Princeton University Press, Princeton.

Wanzenried, G. (2008) How feminine is corporate America? A recent overview, Journal of Economic Inequality, 6, 185-209.

\section{APPENDIX}

This appendix derives the signs of $\frac{d w_{1}}{d t}$ and $\frac{d w_{2}}{d t}$ :

Total differentiating the first order conditions (13a), (13b) and (13c) yields the following matrix equation: 
$\mathbf{A}\left[\begin{array}{c}d \lambda / d t \\ d w_{1} / d t \\ d w_{2} / d t\end{array}\right]=\mathbf{b}^{\mathrm{t}}$

Where:

$\mathbf{A}=\left[\begin{array}{ccc}0 & -\frac{1}{2}(1-t) u^{\prime}\left(y_{1}\right) & -\frac{1}{2}(1-t) u^{\prime}\left(y_{2}\right) \\ -\frac{1}{2}(1-t) u^{\prime}\left(y_{1}\right) & \frac{\partial^{2} \mu}{\partial w_{1}{ }^{2}}-\frac{\lambda}{2}(1-t)^{2} u^{\prime \prime}\left(y_{1}\right) & \frac{\partial^{2} \mu}{\partial w_{1} \partial w_{2}}=0 \\ -\frac{1}{2}(1-t) u^{\prime}\left(y_{2}\right) & \frac{\partial^{2} \mu}{\partial w_{1} \partial w_{2}}=0 & \frac{\partial^{2} \mu}{\partial w_{2}{ }^{2}}-\frac{\lambda}{2}(1-t)^{2} u^{\prime \prime}\left(y_{2}\right)\end{array}\right]$

$\mathbf{b}^{\mathrm{t}}=\left[\begin{array}{c}0 \\ -\frac{\partial^{2} \mu}{\partial w_{1} \partial t}-\frac{1}{2} \lambda\left(u^{\prime}\left(y_{1}\right)+(1-t) w_{1} u^{\prime \prime}\left(y_{1}\right)\right) \\ -\frac{\partial^{2} \mu}{\partial w_{2} \partial t}-\frac{1}{2} \lambda\left(u^{\prime}\left(y_{2}\right)+(1-t) w_{2} u^{\prime \prime}\left(y_{2}\right)\right)\end{array}\right]$

Note that the determinant of the bordered Hessian A has to be positive in order to satisfy the requirement for a maximum. That is:

$|A|=-\left(\frac{1}{2}(1-t) u^{\prime}\left(y_{2}\right)\right)^{2}\left\{\frac{\partial^{2} \mu}{\partial w_{1}{ }^{2}}-\frac{\lambda}{2}(1-t)^{2} u^{\prime \prime}\left(y_{1}\right)\right\}-\left(\frac{1}{2}(1-t) u^{\prime}\left(y_{1}\right)\right)^{2}\left\{\frac{\partial^{2} \mu}{\partial w_{2}{ }^{2}}-\frac{\lambda}{2}(1-t)^{2} u^{\prime \prime}\left(y_{2}\right)\right\}>0$.

Define $\mathbf{A}_{2}^{t}$ and $\mathbf{A}_{3}^{t}$ as:

$\mathbf{A}_{2}^{t}=\left[\begin{array}{ccc}0 & 0 & -\frac{1}{2}(1-t) u^{\prime}\left(y_{2}\right) \\ -\frac{1}{2}(1-t) u^{\prime}\left(y_{1}\right) & -\frac{\partial^{2} \mu}{\partial w_{1} \partial t}-\frac{1}{2} \lambda\left(u^{\prime}\left(y_{1}\right)+(1-t) w_{1} u^{\prime \prime}\left(y_{1}\right)\right) & 0 \\ -\frac{1}{2}(1-t) u^{\prime}\left(y_{2}\right) & -\frac{\partial^{2} \mu}{\partial w_{2} \partial t}-\frac{1}{2} \lambda\left(u^{\prime}\left(y_{2}\right)+(1-t) w_{2} u^{\prime \prime}\left(y_{2}\right)\right) & \frac{\partial^{2} \mu}{\partial w_{2}{ }^{2}}-\frac{\lambda}{2}(1-t)^{2} u^{\prime \prime}\left(y_{2}\right)\end{array}\right]$

$\mathbf{A}_{3}^{t}=\left[\begin{array}{ccc}0 & -\frac{1}{2}(1-t) u^{\prime}\left(y_{1}\right) & 0 \\ -\frac{1}{2}(1-t) u^{\prime}\left(y_{1}\right) & \frac{\partial^{2} \mu}{\partial w_{1}{ }^{2}}-\frac{\lambda}{2}(1-t)^{2} u^{\prime \prime}\left(y_{1}\right) & -\frac{\partial^{2} \mu}{\partial w_{1} \partial t}-\frac{1}{2} \lambda\left(u^{\prime}\left(y_{1}\right)+(1-t) w_{1} u^{\prime \prime}\left(y_{1}\right)\right) \\ -\frac{1}{2}(1-t) u^{\prime}\left(y_{2}\right) & 0 & -\frac{\partial^{2} \mu}{\partial w_{2} \partial t}-\frac{1}{2} \lambda\left(u^{\prime}\left(y_{2}\right)+(1-t) w_{2} u^{\prime \prime}\left(y_{2}\right)\right)\end{array}\right]$

The determinant of $\mathbf{A}_{2}^{t}$ is given by:

$$
\begin{aligned}
\left|\mathbf{A}_{2}^{t}\right|= & \left(\frac{1}{2}(1-t)\right)^{2}\left(u^{\prime}\left(y_{1}\right) u^{\prime}\left(y_{2}\right)\right)\left(-\frac{\partial^{2} \mu}{\partial w_{2} \partial t}-\frac{1}{2} \lambda\left(u^{\prime}\left(y_{2}\right)+(1-t) w_{2} u^{\prime \prime}\left(y_{2}\right)\right)\right) \\
& -\left(\frac{1}{2}(1-t)\right)^{2} u^{\prime}\left(y_{2}\right)^{2}\left(-\frac{\partial^{2} \mu}{\partial w_{1} \partial t}-\frac{1}{2} \lambda\left(u^{\prime}\left(y_{1}\right)+(1-t) w_{1} u^{\prime \prime}\left(y_{1}\right)\right)\right) \\
= & \left(\frac{1}{2}(1-t)\right)^{2}\left[-\left(u^{\prime}\left(y_{1}\right) u^{\prime}\left(y_{2}\right)\right) \frac{\partial^{2} \mu}{\partial w_{2} \partial t}-\frac{1}{2} u^{\prime}\left(y_{1}\right) u^{\prime}\left(y_{2}\right) \lambda\left(u^{\prime}\left(y_{2}\right)+(1-t) w_{2} u^{\prime \prime}\left(y_{2}\right)\right)\right. \\
& \left.+u^{\prime}\left(y_{2}\right)^{2} \frac{\partial^{2} \mu}{\partial w_{1} \partial t}+\frac{1}{2} u^{\prime}\left(y_{2}\right)^{2} \lambda\left(u^{\prime}\left(y_{1}\right)+(1-t) w_{1} u^{\prime \prime}\left(y_{1}\right)\right)\right] \\
= & \left(\frac{1}{2}(1-t)\right)^{2}\left[-\left(u^{\prime}\left(y_{1}\right) u^{\prime}\left(y_{2}\right)\right) \frac{\partial^{2} \mu}{\partial w_{2} \partial t}-\frac{1}{2}\left(u^{\prime}\left(y_{1}\right) u^{\prime}\left(y_{2}\right)^{2}\right) \lambda\left(1-\frac{-(1-t) w_{2} u^{\prime \prime}\left(y_{2}\right)}{u^{\prime}\left(y_{2}\right)}\right)\right. \\
& \left.+u^{\prime}\left(y_{2}\right)^{2} \frac{\partial^{2} \mu}{\partial w_{1} \partial t}+\frac{1}{2} u^{\prime}\left(y_{1}\right) u^{\prime}\left(y_{2}\right)^{2} \lambda\left(1-\frac{-(1-t) w_{1} u^{\prime \prime}\left(y_{1}\right)}{u^{\prime}\left(y_{1}\right)}\right)\right] \\
= & \left(\frac{1}{2}(1-t)\right)^{2}\left[-\left(u^{\prime}\left(y_{1}\right) u^{\prime}\left(y_{2}\right)\right) \frac{\partial^{2} \mu}{\partial w_{2} \partial t}-\frac{1}{2}\left(u^{\prime}\left(y_{1}\right) u^{\prime}\left(y_{2}\right)^{2}\right) \lambda(1-R R A)\right. \\
= & \left.+u^{\prime}\left(y_{2}\right)^{2} \frac{\partial^{2} \mu}{\partial w_{1} \partial t}+\frac{1}{2} u^{\prime}\left(y_{1}\right) u^{\prime}\left(y_{2}\right)^{2} \lambda(1-R R A)\right] \\
= & \left.\frac{1}{2}(1-t)\right)^{2}\left[u^{\prime}\left(y_{2}\right)^{2} \frac{\partial^{2} \mu}{\partial w_{1} \partial t}-\left(u^{\prime}\left(y_{1}\right) u^{\prime}\left(y_{2}\right)\right) \frac{\partial^{2} \mu}{\partial w_{2} \partial t}\right]
\end{aligned}
$$

Thus (B4),(7a) and (7b) imply $\left|A_{2}^{t}\right|<0$ when RRA $<1$, whilst $\left|A_{2}^{t}\right|>0$ when RRA $>1$.

The determinant of $\mathbf{A}_{3}^{t}$ is given by:

$$
\begin{aligned}
\left|A_{3}^{t}\right|=( & \left.\frac{1}{2}(1-t)\right)^{2} u^{\prime}\left(y_{1}\right) u^{\prime}\left(y_{2}\right)\left(-\frac{\partial^{2} \mu}{\partial w_{1} \partial t}-\frac{1}{2} \lambda\left(u^{\prime}\left(y_{1}\right)+(1-t) w_{1} u^{\prime \prime}\left(y_{1}\right)\right)\right) \\
& -\left(\frac{1}{2}(1-t)\right)^{2} u^{\prime}\left(y_{1}\right)^{2}\left(-\frac{\partial^{2} \mu}{\partial w_{2} \partial t}-\frac{1}{2} \lambda\left(u^{\prime}\left(y_{2}\right)+(1-t) w_{2} u^{\prime \prime}\left(y_{2}\right)\right)\right) \\
= & \left(\frac{1}{2}(1-t)\right)^{2}\left[-u^{\prime}\left(y_{1}\right) u^{\prime}\left(y_{2}\right) \frac{\partial^{2} \mu}{\partial w_{1} \partial t}-\frac{1}{2} u^{\prime}\left(y_{1}\right)^{2} u^{\prime}\left(y_{2}\right) \lambda\left(1-\frac{-(1-t) w_{1} u^{\prime \prime}\left(y_{1}\right)}{u^{\prime}\left(y_{1}\right)}\right)\right.
\end{aligned}
$$




$$
\begin{gathered}
\left.+\mathrm{u}^{\prime}\left(\mathrm{y}_{1}\right)^{2} \frac{\partial^{2} \mu}{\partial \mathrm{w}_{2} \partial \mathrm{t}}+\frac{1}{2} \mathrm{u}^{\prime}\left(\mathrm{y}_{1}\right)^{2} \mathrm{u}^{\prime}\left(\mathrm{y}_{2}\right) \lambda\left(1-\frac{-(1-\mathrm{t}) \mathrm{w}_{2} \mathrm{u}^{\prime \prime}\left(\mathrm{y}_{2}\right)}{\mathrm{u}^{\prime}\left(\mathrm{y}_{2}\right)}\right)\right] \\
=\left(\frac{1}{2}(1-t)\right)^{2}\left[-u^{\prime}\left(y_{1}\right) u^{\prime}\left(y_{2}\right) \frac{\partial^{2} \mu}{\partial w_{1} \partial t}-\frac{1}{2} u^{\prime}\left(y_{1}\right)^{2} u^{\prime}\left(y_{2}\right) \lambda(1-R R A)\right. \\
\left.\quad+u^{\prime}\left(y_{1}\right)^{2} \frac{\partial^{2} \mu}{\partial w_{2} \partial t}+\frac{1}{2} u^{\prime}\left(y_{1}\right)^{2} u^{\prime}\left(y_{2}\right) \lambda(1-R R A)\right] \\
=\left(\frac{1}{2}(1-t)\right)^{2}\left[-u^{\prime}\left(y_{1}\right) u^{\prime}\left(y_{2}\right) \frac{\partial^{2} \mu}{\partial w_{1} \partial t}+u^{\prime}\left(y_{1}\right)^{2} \frac{\partial^{2} \mu}{\partial w_{2} \partial t}\right]
\end{gathered}
$$

Thus it follows from ( $\mathrm{B}_{5}$ ), (7a) and (7b) that $\mathbf{A}_{3}^{t}>0$ when RRA $<1$, whilst it follows that $\mathbf{A}_{3}^{t}<0$ when RRA $>1$.

\section{The signs of $\mathrm{dw}_{1} / \mathrm{dt}$ and $\mathrm{dw}_{2} / \mathrm{dt}$ :}

By Cramer's rule we have $\frac{d w_{1}}{d t}=\frac{\left|A_{2}^{t}\right|}{|A|}$ and $\frac{d w_{2}}{d t}=\frac{\left|A_{3}^{t}\right|}{|A|}$

From $\left(\mathrm{B}_{4}\right)$ and $\left(\mathrm{B}_{5}\right)$ and Cramer's rule we have:

Case 1: when $\operatorname{RRA}<1 \frac{d w_{1}}{d t}<0$ and $\frac{d w_{2}}{d t}>0$

Case 2: when RRA $>1 \frac{d w_{1}}{d t}>0$ and $\frac{d w_{2}}{d t}<0$ 